\title{
Genetics of Gestational Trophoblastic Disease
}

Rosemary A Fisher PhD; FRCPath ${ }^{1}$ and Geoffrey J Maher PhD

Trophoblastic Tumour Screening and Treatment Centre, Faculty of Medicine, Imperial College London, Charing Cross Campus, Fulham Palace Road, London, W6 8RF, UK.

${ }^{1}$ To whom correspondence should be addressed at: Department of Oncology, Imperial College London, Charing Cross Campus, Fulham Palace Road, London W6 8RF, UK.

Tel: +44(0)20 3311 1413;

E-mail r.fisher@imperial.ac.uk

The authors have no conflict of interest to declare

Word Count: 6199 


\section{Abstract}

The abnormal pregnancies complete and partial hydatidiform mole are genetically unusual, being associated with two copies of the paternal genome. Typical complete hydatidiform moles are diploid and androgenetic while partial hydatidiform moles are diandric triploids. While diagnosis can usually be made on the basis of morphology, ancillary techniques that exploit their unusual genetic origin can be used to facilitate diagnosis. Genotyping and p57 immunostaining are now routinely used in the differential diagnosis of complete and partial hydatidiform moles, for investigating unusual mosaic or chimeric products of conception with a molar component and identifying the rare diploid, biparental hydatidiform moles associated with an inherited predisposition to molar pregnancies. Genotyping also plays an important role in the differential diagnosis of gestational and non-gestational trophoblastic tumours and identification of the causative pregnancy where tumours are gestational. Recent developments include the use of cell free DNA for noninvasive diagnosis of these conditions.

Key Words: Complete hydatidiform mole, partial hydatidiform mole, familial recurrent hydatidiform mole, p57 immunostaining, genotyping, trophoblastic tumour 


\section{Introduction}

Gestational trophoblastic diseases (GTD) include the premalignant complete (CHM) and partial hydatidiform mole (PHM) together with the malignant conditions invasive mole, choriocarcinoma, placental site (PSTT) and epithelioid trophoblastic tumour (ETT). While morphology underlies the diagnosis of these diseases, an understanding of their genetic basis has enabled the development of ancillary techniques that are now routinely used in the differential diagnosis of both hydatidiform moles (HM) and gestational trophoblastic tumours (GTT). In addition these techniques have led to the identification of unusual subsets of molar pregnancies and enabled refinement of diagnosis, not possible on the basis of morphology alone.

\section{Genetics of Hydatidiform Moles}

(i) Complete and Partial Hydatidiform Moles

$\mathrm{HM}$, or molar pregnancy, an abnormal pregnancy characterised by overgrowth of the placenta and poor fetal development, has an incidence in the UK of $\sim 1$ in 600 conceptions [1]. HM can be classified as CHM or PHM on the basis of pathology and genetics $[2,3]$. Morphologically $\mathrm{CHM}$ are characterized by chorionic villi with budding architecture, stromal karyorrhectic debris and extensive villous trophoblastic hyperplasia. In contrast, villi of PHM are variously sized with scalloped outlines, often have vessels with fetal red blood cells and trophoblastic hyperplasia is focal [4]. Genetically PHM are triploid, having an extra set of chromosomes from the father of the pregnancy. They usually result from fertilisation of an ovum by two sperm $[5,6]$ (Figure 1a) or, very occasionally, a diploid sperm $[7,8]$. While PHM may be $69, \mathrm{XXX}$, 
$69, \mathrm{XXY}$ or $69, \mathrm{XYY}$, the proportion of $69, \mathrm{XYY}$ PHM in most series is considerably lower than the expected $25 \%[8,9]$. CHM are diploid with both sets of chromosomes from the father and no contribution to the nuclear genome from the mother $[10,11]$. While $~ 15-25 \%$ of $\mathrm{CHM}$ arise by dispermy $[8,12]$ (Figure $1 b)$, the majority result from fertilization of an ovum by a single sperm with subsequent reduplication of the sperm genome $[13,14]$ (Figure 1c). Since all monospermic CHM have a female, 46, XX karyotype, 46, $Y Y$ conceptuses are presumed to be non-viable. How, and when, the maternal chromosomes are lost in CHM remains controversial. It has been suggested that loss results during postzygotic diploidisation of a triploid conceptus [15]. However, recent evidence from mouse models [16] supports earlier theories that the ovum may in fact be anucleate when fertilised due to loss of chromosomes or chromatids, to one of the polar bodies, during meiosis.

\section{(ii) Recurrent Hydatidiform Moles}

While most molar pregnancies are sporadic, any woman who has a $\mathrm{HM}$ is at increased risk of a subsequent molar pregnancy, $1 \%$ after a single $\mathrm{HM}$, increasing to $\sim 13 \%$ after two or more $\mathrm{HM}[17]$. Recurrent PHM are rare and are usually interspersed with normal pregnancies [17]. However, a small subset of women with recurrent $\mathrm{CHM}$ have an inherited predisposition to molar pregnancies and subsequent pregnancies are most likely to be further $\mathrm{CHM}$ [17]. This condition, familial recurrent hydatidiform mole (FRHM) is an autosomal recessive disorder characterized by diploid, biparental $\mathrm{CHM}$ (BiCHM), with a chromosomal complement from each parent (Figure 1d), in contrast to the androgenetic origin of typical $\mathrm{CHM}(\mathrm{AnCHM})[18,19]$. Biallelic 
mutations in two maternal effect genes, $\underline{N L R P 7}$ [20] and $\underline{K H D C 3 L}$ [21] account for $\sim 75-80 \%$ and $\sim 5-10 \%$ of cases of FRHM respectively. Women with this condition rarely achieve a normal pregnancy and oocyte donation is usually recommended to ensure normal embryo development [22, 23]. A smaller number of women with recurrent $\mathrm{CHM}$ have recurrent $\mathrm{AnCHM} \mathrm{[17]} \mathrm{but}$ these women may also have normal pregnancies in addition to the $\mathrm{CHM}$, do not have other affected family members and do not have mutations in $\underline{N L R P 7}$ or $\underline{K H D C 3 L}$ [24]. For these women, in vitro fertilisation (IVF) with preimplantation genetic diagnosis, to exclude androgenetic conceptions, can achieve a normal pregnancy [25].

(iii) Genomic Imprinting in Hydatidiform Moles

A small number of mammalian genes, $\sim 100$ in man [26], are unusual in that they are only transcribed from the maternally- or paternally-inherited allele. Expression of the allele inherited from the other parent is suppressed or "imprinted", a phenomenon known as genomic imprinting. Both PHM and AnCHM, have two copies of the paternal genome, exhibit over-expression of paternally-transcribed genes and excessive trophoblastic proliferation. The relatively milder phenotype of PHM including the presence of embryonic development, virtually absent in $\mathrm{CHM}$, is thought to be due to the additional expression of maternally-transcribed genes in $\mathrm{PHM}$. BiCHM in women with either $\underline{N L R P 7}$ or $\underline{K H D C 3 L}$ mutations show loss of maternal imprinting similar to that of AnCHM [27-30] suggesting that NLRP7 and KHDC3L are required for correct imprinting during ovum development and early embryogenesis. Loss of appropriate imprinting results in a molar phenotype for any products of 
conception (POC) in affected women including normal biparental conceptions and digynic triploids [31, 32], genotypes not normally associated with HM.

\section{Differential Diagnosis of Hydatidiform Moles}

A distinction between $\mathrm{CHM}, \mathrm{PHM}$ and non-molar pregnancies is essential as women with a PHM or $\mathrm{CHM}$ have a $1.1 \%$ and $13.6 \%$ chance respectively of requiring chemotherapy for persistent disease following evacuation of the HM [1], whilst the risk for women with non-molar pregnancies is extremely low. Improved antenatal care, earlier recognition of abnormal POC and evacuation at an earlier gestational age has made morphological diagnosis of $\mathrm{HM}$ more difficult in recent years and hence the need for ancillary techniques based on their genetic origin. These techniques are also important for the diagnosis of women with FRHM for whom future pregnancies are almost certain to be $\mathrm{CHM}$ with the associated risk of persistent disease that requires chemotherapy. Although $\mathrm{CHM}$ in these women can sometimes show atypical features [33-35] they are often pathologically indistinguishable from $\mathrm{AnCHM}$ [33]. Diagnosis relies on demonstrating that they are morphologically HM and genetically diploid and biparental, or rarely a digynic triploid, and therefore additional analyses is required for accurate diagnosis.

\section{Ancillary Techniques in the Diagnosis of Hydatidiform Moles}

A number of ancillary techniques have now been used to exploit the unusual genetic origin of $\mathrm{HM}$ and facilitate their diagnosis. Most significant has been the use of p57 immunostaining in the diagnosis of $\mathrm{CHM}$ and genotyping for the, often more difficult, differential diagnosis between PHM and non-molar 
miscarriage. Genotyping has also enabled more accurate diagnosis of FRHM, mosaic conceptions with molar change and aneuploid conceptions.

(i) Immunostaining of p57 in Hydatidiform Moles

$\underline{C D K N 1 C}$, a gene located on chromosome 11 , is maternally-expressed in the nuclei of both the villous cytotrophoblast and stroma. Thus, immunohistochemical staining for its protein product, p57, can be used to distinguish between $\mathrm{CHM}$ (which lack staining due to the absence of a maternal genome) [36-37] and all other POC that express p57 in these cells (Figure 2). As $\underline{C D K N 1 C}$ is not imprinted in the extravillous trophoblast, expression of p57 is retained in these cells, even in $\mathrm{CHM}$, providing a useful internal control for the staining procedure. While p57 immunostaining cannot distinguish PHM from non-molar miscarriages, it can play a role in the differential diagnosis of PHM from CHM with coexistent twin pregnancy. In PHM all villi show positivity but in a twin pregnancy both a positive and a negative population of villi are seen [38]. p57 immunostaining may also be useful confirmation that a diploid conception with atypical morphology is a $\mathrm{BiCHM}$ rather than a non-molar pregnancy since, like typical AnCHM, BiCHM are usually p57-negative [28]. p57 immunostaining and morphology may occasionally appear inconsistent and caution should be applied in these rare cases. For example POC, that are morphologically CHM, may express p57 due to retention of a maternal chromosome $11[39,40]$ while PHM may be p57-negative due to loss of the maternal copy of chromosome 11 [41]. 
A consequence of the wider use of p57 immunostaining has been greater observation of mosaic POC with a molar component, in particular POC comprising two populations of diploid cells, one normal and one androgenetic [42]. These androgenetic/biparental conceptions, comprising up to $2 \%$ of POC referred for suspected HM [43], show a wide range of discordant (Figure 2c-d) and divergent p57 expression within and between placental villi [44, 45]. While not often having the typical morphology of $\mathrm{CHM}$ it is clinically important to recognise these conceptions because of the malignant potential the presence of the androgenetic cell line confers [43, 46].

(ii) Genotyping in the Diagnosis of Hydatidiform Moles

Since early studies using chromosomal polymorphisms identified the genetic origin of $\mathrm{HM}$, a number of different types of DNA polymorphisms have been used in the diagnosis of GTD. Currently, microsatellite polymorphisms, based on short tandem repeats (STR) and amenable to amplification using the polymerase chain reaction (PCR), have made rapid genotyping of DNA from formalin-fixed, paraffin-embedded tissue sections feasible. Cells of interest, usually maternal decidua and molar villi, can be identified from haematoxylin and eosin stained sections, dissected manually or by laser capture microdissection from adjacent unstained sections and used for DNA preparation. PCR amplification of the DNA using fluorescently-labelled primers that target multiple STR loci on different chromosomes and subsequent sizing of the PCR products by capillary electrophoresis can be used to identify STR in the DNA of the molar tissue. These are then 
compared with those in the patient (using DNA from blood or maternal decidua) and her partner (if available) (Figure 3).

Typical AnCHM have one, or occasionally both, paternal allele(s) with no maternal contribution, at informative loci (Figure 3a). Where a DNA sample from the father is not available, diagnosis is made by demonstrating nonmaternal (i.e. paternal) alleles in DNA from the molar tissue. A single allele at each locus indicates a monospermic $\mathrm{CHM}$ while the presence of two paternal alleles at some loci indicates the less common dispermic $\mathrm{CHM}$, a distinction that cannot be made on the basis of morphology alone. The more malignant potential of dispermic $\mathrm{CHM}$, initially suggested by small studies, remains controversial in larger studies $[47,48]$ and at present the distinction between monospermic and dispermic $\mathrm{HM}$ is not routinely made. Demonstration that POC with molar pathology and an absence of p57 staining are diploid and biparental (Figure 4), or rarely a digynic triploid, enables a diagnosis of FRHM and should be followed with sequencing of $\underline{N L R P 7}$ and/or $\underline{K H D C 3 L}$ in the patient. Identification of the specific mutations involved can play an important role in enabling screening of other family members, particularly important for nulliparous female siblings. However, absence of mutations should not exclude a diagnosis of $\mathrm{FRHM}$, as $\sim 10 \%$ of patients do not have mutations in these genes $[49,50]$.

With the routine use of p57 immunostaining, the more difficult differential diagnosis is between PHM and non-molar miscarriages. A number of conditions may be pathologically difficult to distinguish from PHM, including 
Beckwith-Wiedemann syndrome [51, 52], placental mesenchymal dysplasia [51] and a number of chromosomal abnormalities, in particular paternal isodisomy for the short arm of chromosome 11 [53] and trisomy 13 [54, 55]. Since these conditions are essentially diploid they can be distinguished from triploid PHM that have three alleles, or two alleles of disproportionate height, at each locus (Figure 3b). Demonstrating that two of the alleles at each locus are paternally-derived, and one maternal, identifies a PHM, rather than a digynic triploid, in which the extra chromosomal complement is maternal in origin. Genotyping is now widely used to discriminate between non-molar miscarriage, $\mathrm{PHM}$ and $\mathrm{CHM}[8,56]$ and provide accurate diagnosis in cases of probable or possible PHM [9]. Dissection and genotyping of populations of villi with divergent or discordant p57 staining patterns can also be used to differentiate PHM from $\mathrm{CHM}$ with coexistent twin and identify the presence of any potentially malignant, androgenetic cell line in the case of mosaic or chimeric conceptuses.

Finally genotyping can identify unusual cases that are not regular diploids or triploids. HM have occasionally been shown to be tetraploid with most tetraploid PHM being shown to arise by trispermy, rather than two sperm, one of which is diploid [8]. However, tetraploid CHM are more difficult to identify as like diploid $\mathrm{CHM}$, they will usually have a single allele at each locus. In most series of $\mathrm{HM}$ occasional aneuploid cases, essentially $\mathrm{CHM}$ or PHM with loss or gain of one or more maternally- or paternally-derived chromosomes [39-41, 57-59], have been described. These aneuploid cases, which appear to be most commonly associated with dispermic $\mathrm{CHM}$ [60], can be resolved by 
genotyping with a panel of STR, that cover loci on all chromosomes, or single nucleotide polymorphism-based microarray analysis [60]. While genotyping plays an important role in different scenarios, it must be considered in the context of morphology and p57 immunostaining to avoid misinterpretation of unusual cases. A number of algorithms for combining morphology, p57 and genotyping, in the diagnosis of suspected HM, have now been proposed [56, 61].

\section{Genetics of Gestational Trophoblastic Tumours}

GTT are characterised by trophoblastic differentiation of the tumour tissue and production of serum human chorionic gonadotropin (hCG). The tumours can arise from $\mathrm{CHM}, \mathrm{PHM}$ or any non-molar pregnancy with their genetic makeup reflecting the pregnancy of origin. The proportion arising from different types of pregnancy varies across tumour subtypes. Whilst all invasive moles derive from molar pregnancies, the majority originating in $\mathrm{CHM}$ [48], only $~ 50 \%$ of choriocarcinoma and $\sim 25 \%$ of PSTT/ETT have a molar origin [62]. Surprisingly, although $\sim$ half of the tumours arising in non-molar pregnancies would be expected to be male, for reasons that remain unexplained, the vast majority of PSTT/ETT originate from genetically female pregnancies [63-65]. Establishing the causative pregnancy, which may not be the antecedent pregnancy [66], is particularly important for a patient with PSTT or ETT, where a time interval of less or greater than four years has clear prognostic significance $[67,68]$. 
Genetically, GTT are poorly characterised at the molecular level.

Chromosomal loss or gain [69-72], complex chromosomal rearrangements [73] and rare copy number variants [74] have been described but only in a minority of cases. To date GTT have not been associated with any consistent genetic abnormalities nor has any genetic marker of tumour subtype been identified. Further investigations are needed to determine if this is due to limited investigation of these rare tumours or whether other factors drive tumorigenesis. The relatively high risk of requiring chemotherapy following a CHM and lesser, but still increased, risk after a PHM suggests aberrant genomic imprinting is likely to play a role in the development of post-mole tumours. Recent analysis of DNA from an intraplacental choriocarcinoma, revealed a very different methylation profile for the tumour and the surrounding normal term placenta, suggesting that epigenetic changes, rather than an accumulation of mutations, may also have a role in the development of tumours following non-molar pregnancies [75].

\section{Differential Diagnosis of Trophoblastic Tumours}

While raised serum hCG is the hallmark of GTT, tumours of non-gestational origin, particularly more aggressive tumours, may also secrete hCG [76]. Nongestational trophoblastic tumours are biologically different, less chemosensitive and have a poor prognosis compared to GTT where overall survival is greater than $90 \%$ [77]. A differential diagnosis between a gestational and non-gestational tumour is therefore important for patient management. While this can usually be made on the basis of clinical criteria, it becomes more problematic where these tumours also show trophoblastic 
differentiation which may be seen in some high grade carcinoma, metastatic lesions originating in different primaries and as a component of ovarian germ cell tumours [66, 78-81]. Conversely gestational choriocarcinoma and ETT may occasionally mimic non-gestational tumours [78, 82].

\section{Ancillary Techniques in the Diagnosis of Trophoblastic Tumours}

(i) Genotyping in the Diagnosis of Trophoblastic Tumours

As differential diagnosis of trophoblastic tumours relies on demonstrating the presence or absence of a paternal contribution to the tumour genome, p57 immunostaining is less relevant and STR genotyping is currently the gold standard. Manual microdissection of tumour and surrounding host tissue is usually satisfactory for DNA preparation. However, if tumours are small and are infiltrating the host tissue, or are themselves infiltrated by host lymphocytes, laser capture microdissection of the cells of interest might be considered in order to minimise contamination from host cells [71]. While analysis can be performed using pathological sections alone, analysis of DNA from the patient and her partner can be useful in confirming diagnosis. A patient sample is essential when the tissue sample is a small biopsy containing only tumour cells.

A GTT will have one or more paternal contributions to the genome, with the genotype reflecting the pregnancy of origin (Figure 5a). As with diagnosis of $\mathrm{HM}$, if samples from the partner are not available, the presence of alleles in DNA from the tumour, not present in the patient, are assumed to be paternal in origin. However, when paternal samples are not available, caution should 
be taken to avoid misdiagnosis. For example a non-gestational tumour in a patient with Lynch syndrome may have a high degree of instability suggesting a non-maternal component and falsely suggest an androgenetic tumour [80], as might a case where the patient has a history of IVF with a donor ovum and the maternal contribution is therefore different to that of the patient [83]. Factoring in the morphology and clinical history is recommended to avoid misdiagnosis of such unusual cases. The genotype of a non-gestational tumour reflects that of the patient with no evidence of a paternal contribution (Figure 5b). Since microdissection of tumour and host tissue for DNA preparation is performed from the same unstained sections and the genotype of the host and tumour are potentially identical at the loci examined, care must be taken to ensure that the DNA analysed is from tumour cells and not obscured by DNA from host cells, particularly important where tumours are small and there is a high degree of infiltration by host cells such as lymphocytes. Demonstrating loss of heterozygosity or allelic imbalance in the tumour DNA, compared to that of the host, can provide confirmation that the DNA analysed is tumour-derived [80] (Figure 5b).

Genotyping of tumour DNA can identify the nature of the causative pregnancy. However, additional genotyping of DNA from previous miscarriages, molar pregnancies and/or DNA from saliva of live born children is needed to identify the specific pregnancy. While choriocarcinoma have sometimes been shown to arise from an earlier pregnancy, including unrecognised $\mathrm{CHM}[66,78,79]$, with or without intervening pregnancies [66], PSTT and ETT less frequently originate in earlier pregnancies [65]. It has 
recently been found that some cases of ETT and PSTT are associated with atypical placental site nodules (APSN), $10-15 \%$ of patients with APSN subsequently being diagnosed with PSTT or ETT [84]. Again the causative pregnancy of the APSN can be determined by genotyping the offspring or POC from the patient. Genotyping has also provided interesting insights into the causative pregnancy in intraplacental choriocarcinomas. These might be expected to arise from the surrounding villous tissue of the placenta in which they originated but it has now been shown they may originate in earlier, or coexistent but genetically different, pregnancies [85], or be non-gestational [80].

(ii) Non-invasive Diagnosis of Trophoblastic Tumours

While diagnosis of GTD usually relies on trophoblastic tissue it is occasionally considered safer to treat a patient with a trophoblastic tumour on the basis of a clinical diagnosis rather than perform surgery. In these cases it has been shown that cell free DNA (cfDNA), isolated from the patient's plasma, can provide a source of circulating tumour DNA (ctDNA) for genotyping $[86,87]$ and potentially diagnose both gestational and non-gestational tumours [87]. While these techniques currently lack sensitivity, particularly in women with a small tumour burden [87] or involve complex and time-consuming technology [88], the use of ctDNA holds considerable potential for non-invasive diagnosis of GTD and providing further resources for investigating these conditions.

\section{Summary}

p57 and genotyping are important ancillary techniques in the differential diagnosis and management of GTD. Since all types of placenta, with the 
exception of $\mathrm{CHM}$, show p57-positive staining of the villous cytotrophoblast and stroma, immunostaining will identify CHM. Since PHM are triploid with two paternal contributions to the genome, genotyping can differentiate PHM from other types of reproductive loss. Genotyping also enables diagnosis of FRHM by showing recurrent $\mathrm{CHM}$ are diploid and biparental. A combination of p57 immunostaining and genotyping can help resolve diagnosis of unusual cases of molar pregnancy with atypical pathology, particularly mosaic or chimeric conceptions with a molar component or aneuploid molar pregnancies with features of a HM. A tumour showing trophoblastic differentiation, in women with raised levels of serum human chorionic gonadotrophin, may not always be a GTT. A gestational origin can be confirmed by using genotyping to demonstrate the presence of paternally-derived DNA in the tumour. Genotyping can also be used to identify the causative pregnancy in GTT, particularly important for women with PSTT or ETT where the time interval between the causative pregnancy and tumour diagnosis has prognostic significance. Where tumour tissue is not available for investigation, circulating tumour DNA, isolated from the patient's plasma, can be used to facilitate diagnosis.

\section{Acknowledgements}

The authors gratefully acknowledge infrastructure support from the Cancer Research UK Imperial Centre, the Imperial Experimental Cancer Medicine Centre and the National Institute for Health Research Imperial Biomedical Research Centre. 


\section{References}

[1] Savage PM, Sita-Lumsden A, Dickson S, lyer R, Everard J, Coleman R, et al. The relationship of maternal age to molar pregnancy incidence, risks for chemotherapy and subsequent pregnancy outcome. J Obstet Gynaecol 2013;33:406-11.

[2] ${ }^{\star}$ Szulman AE, Surti U. The syndromes of hydatidiform mole. I. Cytogenetic and morphologic correlations. Am J Obstet Gynecol 1978;131:665-71.

[3] Szulman AE, Surti U. The syndromes of hydatidiform mole. II. Morphologic evolution of the complete and partial mole. Am J Obstet Gynecol 1978;132:20-7.

[4] Sebire NJ. Histopathological diagnosis of hydatidiform mole: contemporary features and clinical implications. Fetal Pediatr Pathol 2010;29:1-16.

[5] Lawler SD, Fisher RA, Pickthall VJ, Povey S, Evans MW. Genetic studies on hydatidiform moles. I. The origin of partial moles. Cancer Genet Cytogenet 1982;5:309-20.

[6] Jacobs PA, Szulman AE, Funkhouser J, Matsuura JS, Wilson CC. Human triploidy: relationship between parental origin of the additional haploid complement and development of partial hydatidiform mole. Ann Hum Genet 1982;46:223-31.

[7] Savage P, Sebire N, Dalton T, Carby A, Seckl MJ, Fisher RA. Partial molar pregnancy after intracytoplasmic sperm injection occurring as a result of diploid sperm usage. J Assist Reprod Genet 2013;30:761-4. 
$[8]^{\star}$ Xing D, Adams E, Huang J, Ronnett BM. Refined diagnosis of hydatidiform moles with p57 immunohistochemistry and molecular genotyping: updated analysis of a prospective series of 2217 cases. Mod Pathol 2020; Online ahead of print.

[9] Fisher RA, Tommasi A, Short D, Kaur B, Seckl MJ, Sebire NJ. Clinical Utility of Selective Molecular Genotyping for Diagnosis of Partial Hydatidiform Mole; Retrospective Study from a Regional Trophoblastic Disease Unit. J Clin Pathol 2015;67:980-4.

$[10]^{\star}$ Kajii T, Ohama K. Androgenetic origin of hydatidiform mole. Nature 1977;268:633-4.

[11] Wake N, Takagi N, Sasaki M. Androgenesis as a cause of hydatidiform mole. J Natl Cancer Inst 1978;60:51-7.

[12] Fisher RA, Povey S, Jeffreys AJ, Martin CA, Patel I, Lawler SD. Frequency of heterozygous complete hydatidiform moles, estimated by locusspecific minisatellite and $\mathrm{Y}$ chromosome-specific probes. Hum Genet 1989;82:259-63.

[13] Jacobs PA, Hunt PA, Matsuura JS, Wilson CC, Szulman AE. Complete and partial hydatidiform mole in Hawaii: cytogenetics, morphology and epidemiology. Br J Obstet Gynaecol 1982;89:258-66.

[14] Lawler SD, Povey S, Fisher RA, Pickthall VJ. Genetic studies on hydatidiform moles. II. The origin of complete moles. Ann Hum Genet 1982;46:209-22. 
[15] Golubovsky MD. Postzygotic diploidization of triploids as a source of unusual cases of mosaicism, chimerism and twinning. Hum Reprod 2003;18:236-42.

[16] Nguyen NMP, Ge ZJ, Reddy R, Fahiminiya S, Sauthier P, Bagga R, et al. Causative Mutations and Mechanism of Androgenetic Hydatidiform Moles. Am J Hum Genet 2018;103:740-51.

$[17]^{\star}$ Eagles N, Sebire NJ, Short D, Savage PM, Seckl MJ, Fisher RA. Risk of recurrent molar pregnancies following complete and partial hydatidiform moles. Hum Reprod 2015;30:2055-63.

[18] Helwani MN, Seoud M, Zahed L, Zaatari G, Khalil A, Slim R. A familial case of recurrent hydatidiform molar pregnancies with biparental genomic contribution. Hum Genet 1999;105:112-5.

[19] Fisher RA, Khatoon R, Paradinas FJ, Roberts AP, Newlands ES.

Repetitive complete hydatidiform mole can be biparental in origin and either male or female. Hum Reprod 2000;15:594-8.

[20] Murdoch S, Djuric U, Mazhar B, Seoud M, Khan R, Kuick R, et al. Mutations in NALP7 cause recurrent hydatidiform moles and reproductive wastage in humans. Nat Genet 2006;38:300-2.

[21] Parry DA, Logan CV, Hayward BE, Shires M, Landolsi H, Diggle C, et al. Mutations causing familial biparental hydatidiform mole implicate c6orf221 as a possible regulator of genomic imprinting in the human oocyte. Am J Hum Genet 2011;89:451-8. 
[22] Fisher RA, Lavery SA, Carby A, Abu-Hayyeh S, Swingler R, Sebire NJ, et al. What a difference an egg makes. Lancet 2011;378:1974.

[23] Akoury E, Gupta N, Bagga R, Brown S, Déry C, Kabra M, et al. Live births in women with recurrent hydatidiform mole and two NLRP7 mutations. Reprod Biomed Online 2015;31:120-4.

[24] Dixon PH, Trongwongsa P, Abu-Hayyah S, Ng SH, Akbar SA, Khawaja NP, et al. Mutations in NLRP7 are associated with diploid biparental hydatidiform moles, but not androgenetic complete moles. J Med Genet 2012;49:206-11.

[25] Ogilvie CM, Renwick PJ, Khalaf Y, Braude PR. First use of preimplantation genotyping in prevention of recurrent diandric complete hydatidiform mole. Reprod Biomed Online 2009;19:224-7.

[26] https://www.geneimprint.com

[27] Judson H, Hayward BE, Sheridan E, Bonthron DT. A global disorder of imprinting in the human female germ line. Nature 2002;416:539-42.

[28] Fisher RA, Hodges MD, Rees HC, Sebire NJ, Seckl MJ, Newlands ES, et al. The maternally transcribed gene p57(KIP2) (CDNK1C) is abnormally expressed in both androgenetic and biparental complete hydatidiform moles. Hum Mol Genet 2002;11:3267-72.

[29] Sanchez-Delgado M, Martin-Trujillo A, Tayama C, Vidal E, Esteller M, Iglesias-Platas I, et al. Absence of Maternal Methylation in Biparental Hydatidiform Moles from Women with NLRP7 Maternal-Effect Mutations 
Reveals Widespread Placenta-Specific Imprinting. PLoS Genet 2015;11:e1005644.

[30] Demond H, Anvar Z, Jahromi BN, Sparago A, Verma A, Davari M, et al. A KHDC3L mutation resulting in recurrent hydatidiform mole causes genomewide DNA methylation loss in oocytes and persistent imprinting defects postfertilisation. Genome Med 2019;11:84.

[31] Fallahian M, Sebire NJ, Savage PM, Seckl MJ, Fisher RA. Mutations in NLRP7 and KHDC3L confer a complete hydatidiform mole phenotype on digynic triploid conceptions. Hum Mutat 2013;34:301-8.

[32] Allias F, Mechtouf N, Gaillot-Durand L, Hoffner L, Hajri T, DevouassouxShisheboran M, et al. A novel NLRP7 protein-truncating mutation associated with discordant and divergent p57 immunostaining in diploid biparental and triploid digynic moles. Virchows Arch 2020;477:309-15.

[33] Sebire NJ, Savage PM, Seckl MJ, Fisher RA. Histopathological features of biparental complete hydatidiform moles in women with NLRP7 mutations. Placenta 2013;34:50-6.

[34] Brown L, Mount S, Reddy R, Slim R, Wong C, Jobanputra V, et al. Recurrent pregnancy loss in a woman with NLRP7 mutation: not all molar pregnancies can be easily classified as either "partial" or "complete" hydatidiform moles. Int J Gynecol Pathol 2013;32:399-405.

[35] Nguyen NM, Zhang L, Reddy R, Déry C, Arseneau J, Cheung A, et al. Comprehensive genotype-phenotype correlations between NLRP7 mutations 
and the balance between embryonic tissue differentiation and trophoblastic proliferation. J Med Genet 2014;51:623-34.

[36] Chilosi M, Piazzola E, Lestani M, Benedetti A, Guasparri I, Granchelli G, et al Differential expression of p57kip2, a maternally imprinted cdk inhibitor, in normal human placenta and gestational trophoblastic disease. Lab Invest 1998;78:269-76.

[37] Castrillon DH, Sun D, Weremowicz S, Fisher RA, Crum CP, Genest DR. Discrimination of complete hydatidiform mole from its mimics by immunohistochemistry of the paternally imprinted gene product p57KIP2. Am J Surg Pathol 2001;25:1225-30.

[38] Genest DR, Dorfman DM, Castrillon DH. Ploidy and imprinting in hydatidiform moles. Complementary use of flow cytometry and immunohistochemistry of the imprinted gene product p57KIP2 to assist molar classification. J Reprod Med 2002;47:342-6.

[39] Fisher RA, Nucci MR, Thaker HM, Weremowicz S, Genest DR, Castrillon $\mathrm{DH}$. Complete hydatidiform mole retaining a chromosome 11 of maternal origin: molecular genetic analysis of a case. Mod Pathol 2004;17:1155-60.

[40] McConnell TG, Norris-Kirby A, Hagenkord JM, Ronnett BM, Murphy KM. Complete hydatidiform mole with retained maternal chromosomes 6 and 11 . Am J Surg Pathol 2009;33:1409-15.

[41] DeScipio C, Haley L, Beierl K, Pandit AP, Murphy KM, Ronnett BM. Diandric triploid hydatidiform mole with loss of maternal chromosome 11. Am 
J Surg Pathol 2011;35:1586-91.

[42] Makrydimas G, Sebire NJ, Thornton SE, Zagorianakou N, Lolis D, Fisher RA. Complete hydatidiform mole and normal live birth: a novel case of confined placental mosaicism: case report. Human reproduction 2002;17:2459-63.

[43] Lewis GH, DeScipio C, Murphy KM, Haley L, Beierl K, Mosier S, et al. Characterization of androgenetic/biparental mosaic/chimeric conceptions, including those with a molar component: morphology, p57 immnohistochemistry, molecular genotyping, and risk of persistent gestational trophoblastic disease. Int J Gynecol Pathol 2013;32:199-214.

[44] Hoffner L, Dunn J, Esposito N, Macpherson T, Surti U. P57KIP2 immunostaining and molecular cytogenetics: combined approach aids in diagnosis of morphologically challenging cases with molar phenotype and in detecting androgenetic cell lines in mosaic/chimeric conceptions. Hum Pathol 2008;39:63-72.

[45] Gaillot-Durand L, Patrier S, Aziza J, Devisme L, Riera AC, Marcorelles $\mathrm{P}$, et al. p57-discordant villi in hydropic products of conception: a clinicopathological study of 70 cases. Hum Pathol 2020;101:18-30.

[46] Surti U, Hoffner L, Kolthoff M, Dunn J, Hunt J, Sniezek L, Macpherson T. Persistent gestational trophoblastic disease after an androgenetic/biparental fetal chimera: a case report and review. Int J Gynecol Pathol 2006;25:366-72.

[47] Zheng XZ, Qin XY, Chen SW, Wang P, Zhan Y, Zhong PP, et al. 
Heterozygous/dispermic complete mole confers a significantly higher risk for post-molar gestational trophoblastic disease. Mod Pathol 2020;33:1979-88.

[48] Bynum J, Murphy KM, DeScipio C, Beierl K, Adams E, Anderson D, et al. Invasive Complete Hydatidiform Moles: Analysis of a Case Series With Genotyping. Int J Gynecol Pathol 2016;35:134-41.

[49] Wang CM, Dixon PH, Decordova S, Hodges MD, Sebire NJ, Ozalp S, et al. Identification of 13 novel NLRP7 mutations in 20 families with recurrent hydatidiform mole; missense mutations cluster in the leucine-rich region. $J$ Med Genet 2009;46:569-75.

[50] Hayward BE, De Vos M, Talati N, Abdollahi MR, Taylor GR, Meyer E, et al. Genetic and epigenetic analysis of recurrent hydatidiform mole. Hum Mutat 2009;30:E629-39.

[51] Genest DR. Partial hydatidiform mole: clinicopathological features, differential diagnosis, ploidy and molecular studies, and gold standards for diagnosis. Int J Gynecol Pathol 2001;20:315-22.

[52] Paradinas FJ, Sebire NJ, Fisher RA, Rees HC, Foskett M, Seckl MJ, Newlands ES. Pseudo-partial moles: placental stem vessel hydrops and the association with Beckwith-Wiedemann syndrome and complete moles. Histopathology 2001;39:447-54.

[53] Buza N, McGregor SM, Barroilhet L, Zheng X, Hui P. Paternal uniparental isodisomy of tyrosine hydroxylase locus at chromosome 11p15.4: spectrum of 
phenotypical presentations simulating hydatidiform moles. Mod Pathol 2019;32:1180-8.

[54] Jauniaux E, Halder A, Partington C. A case of partial mole associated with trisomy 13. Ultrasound Obstet Gynecol 1998;11:62-4.

[55] Curtin WM, Marcotte MP, Myers LL, Brost BC. Trisomy 13 appearing as a mimic of a triploid partial mole. J Ultrasound Med 2001;20:1137-9.

[56] ${ }^{\star}$ Hui P, Buza N, Murphy KM, Ronnett BM. Hydatidiform Moles: Genetic Basis and Precision Diagnosis. Annu Rev Pathol 2017;12:449-85.

[57] Dube V, Chun K, Osborne R, Sherman C, Nofech-Mozes S, Ismiil N, et al. Androgenetic complete mole with trisomy 13: report of a case with microsatellite genotyping and review of the literature. Pathol Res Pract 2010;206:776-81.

[58] Norris-Kirby A, Hagenkord JM, Kshirsagar MP, Ronnett BM, Murphy KM. Abnormal villous morphology associated with triple trisomy of paternal origin. J Mol Diagn 2010;12:525-9.

[59] Sebire NJ, May PC, Kaur B, Seckl MJ, Fisher RA. Abnormal villous morphology mimicking a hydatidiform mole associated with paternal trisomy of chromosomes $3,7,8$ and unipaternal disomy of chromosome 11. Diagn Pathol 2016;11:20.

[60] Usui H, Sato A, Shozu M. Parental contribution to trisomy in heterozygous androgenetic complete moles. Scientific Reports $2020 ; 10: 17137$. 
[61] Ronnett BM. Hydatidiform Moles: Ancillary Techniques to Refine Diagnosis. Arch Pathol Lab Med 2018;142:1485-502.

[62] Genest DR, Berkowitz RS, Fisher RA, Newlands ES, Fehr M. Gestational trophoblastic disease. In: Tavassoli FA, Devilee P, editors. World Health Organisation Classification of Tumours. Pathology and genetics of tumours of the breast and female genital organs, Lyon: IARC Press; 2003, p.250-4.

[63] Hui P, Wang HL, Chu P, Yang B, Huang J, Baergen RN, et al. Absence of $Y$ chromosome in human placental site trophoblastic tumor. Mod Pathol 2007;20:1055-60.

[64] Yap KL, Hafez MJ, Mao TL, Kurman RJ, Murphy KM, Shih le M. Lack of a $y$-chromosomal complement in the majority of gestational trophoblastic neoplasms. J Oncol 2010;364508.

[65] Zhao S, Sebire NJ, Kaur B, Seckl MJ, Fisher RA. Molecular genotyping of placental site and epithelioid trophoblastic tumours; female predominance. Gynecol Oncol 2016;142:501-7.

[66] Fisher RA, Savage PM, MacDermott C, Hook J, Sebire NJ, Lindsay I, Seckl MJ. The impact of molecular genetic diagnosis on the management of women with hCG-producing malignancies. Gynecol Oncol 2007;107:413-9.

[67] Schmid P, Nagai Y, Agarwal R, Hancock B, Savage PM, Sebire NJ, et al. Prognostic markers and long-term outcome of placental-site trophoblastic tumours: a retrospective observational study. Lancet 2009;374:48-55.

[68] Froeling FEM, Ramaswami R, Papanastasopoulos P, Kaur B, Sebire NJ, 
Short D, et al. Intensified therapies improve survival and identification of novel prognostic factors for placental-site and epithelioid trophoblastic tumours. $\mathrm{Br} \mathrm{J}$ Cancer 2019;120:587-94.

[69] Matsuda T, Sasaki M, Kato H, Yamada H, Cohen M, Barrett JC, et al. Human chromosome 7 carries a putative tumor suppressor gene(s) involved in choriocarcinoma. Oncogene 1997;15:2773-81.

[70] Ahmed MN, Kim K, Haddad B, Berchuck A, Qumsiyeh MB. Comparative genomic hybridization studies in hydatidiform moles and choriocarcinoma: amplification of 7q21-q31 and loss of 8p12-p21 in choriocarcinoma. Cancer Genet Cytogenet 2000;116:10-5.

[71] Burke B, Sebire NJ, Moss J, Hodges MD, Seckl MJ, Newlands ES, Fisher RA. Evaluation of deletions in 7q11.2 and 8p12-p21 as prognostic indicators of tumour development following molar pregnancy. Gynecol Oncol 2006;103:642-8.

[72] Hui P, Riba A, Pejovic T, Johnson T, Baergen RN, Ward D. Comparative genomic hybridization study of placental site trophoblastic tumour: a report of four cases. Mod Pathol 2004;17:248-51.

[73] Poaty H, Coullin P, Peko JF, Dessen P, Diatta AL, Valent A, et al. Genome-wide high-resolution aCGH analysis of gestational choriocarcinomas. PLoS One 2012;7:e29426.

[74] Mello JB, Ramos Cirilo PD, Michelin OC, Custódio Domingues MA, Cunha Rudge MV, Rogatto SR, Maestá I. Genomic profile in gestational and 
non-gestational choriocarcinomas. Placenta 2017;50:8-15.

[75] Savage P, Monk D, Hernandez Mora JR, van der Westhuizen N, Rauw J, et al. A case of intraplacental gestational choriocarcinoma; characterised by the methylation pattern of the early placenta and an absence of driver mutations. BMC Cancer 2019;19:744.

[76] Stenman UH, Alfthan H, Hotakainen K. Human chorionic gonadotropin in cancer. Clin Biochem 2004;37:549-61.

[77] Ngan HYS, Seckl MJ, Berkowitz RS, Xiang Y, Golfier F, Sekharan PK, et al. Update on the diagnosis and management of gestational trophoblastic disease. Int J Gynaecol Obstet 2018;143 Suppl 2:79-85.

[78] Aranake-Chrisinger J, Huettner PC, Hagemann AR, Pfeifer JD. Use of short tandem repeat analysis in unusual presentations of trophoblastic tumors and their mimics. Hum Pathol 2016;52:92-100.

[79] ${ }^{\star}$ Savage J, Adams E, Veras E, Murphy KM, Ronnett BM.

Choriocarcinoma in Women: Analysis of a Case Series With Genotyping. Am J Surg Pathol 2017; 41:1593-606.

$[80]^{\star}$ Fisher RA, Kaur, B. Molecular genotyping in the diagnosis of trophoblastic tumours. Diagn Histopathol 2019:25;66-76.

[81] Buza N, Baine I, Hui P. Precision genotyping diagnosis of lung tumors with trophoblastic morphology in young women. Mod Pathol 2019;32:1271-80. [82] Patten DK, Lindsay I, Fisher RA, Sebire N, Savage PM, Seckl MJ. 
Gestational choriocarcinoma mimicking a uterine adenocarcinoma. J Clin Oncol 2008;26:5126-7.

[83] Khan S, Dancey G, Lindsay I, Sebire NJ, Fisher RA, Seckl MJ, et al. Placental site trophoblastic tumour derived from an oocyte donation pregnancy. BJOG 2006;113:344-6.

[84] Kaur B, Short D, Fisher RA, Savage PM, Seckl MJ, Sebire NJ. Atypical Placental Site Nodule (APSN) and Association With Malignant Gestational Trophoblastic Disease; A Clinicopathologic Study of 21 Cases. Int J Gynecol Pathol 2015;34:152-8.

[85] Yamamoto E, Niimi K, Shinjo K, Yamamoto T, Fukunaga M, Kikkawa F. Identification of causative pregnancy of gestational trophoblastic neoplasia diagnosed during pregnancy by short tandem repeat analysis. Gynecol Oncol Case Rep 2014;9:3-6.

[86] Kristiansen MK, Niemann I, Lindegaard JC, Christiansen M, Joergensen MW, Vogel I, et al. Cell-free DNA in pregnancy with choriocarcinoma and coexistent live fetus: A case report. Medicine (Baltimore) 2016; 95: e4721.

[87] Openshaw MR, Harvey RA, Sebire NJ, Kaur B, Sarwar N, Seckl MJ et al. Circulating Cell Free DNA in the Diagnosis of Trophoblastic Tumors. EBioMedicine 2015; 4: 146-152.

[88] Lavoie J-M, Alcaide M, Fisher RA, Seckl MJ, Morin R, Tinker AV. Targeted Error-Suppressed Detection of Circulating Paternal DNA to Establish a Diagnosis of Gestational Trophoblastic Neoplasm. JCO Precision 
Oncology 2017;1:1-6. 


\section{FIGURE LEGENDS}

\section{Figure 1: Genetic origin of hydatidiform moles}

(a) PHM are triploid and almost all arise by dispermy (b) Some CHM also arise by dispermy, with loss of the maternal chromosomes (c) The majority of $\mathrm{CHM}$ arise from fertilization of an ovum by a single sperm, loss of the maternal chromosomes and duplication of the sperm genome (d) $\mathrm{BiCHM}$ arise following normal fertilization of an ovum in a woman with biallelic mutations of $\underline{N L R P 7}$ or $\underline{K H D C 3 L}$.

\section{Figure 2: Photomicrographs of p57 immunostaining}

(a) $\mathrm{CHM}$ with no p57 immunostaining in the villous cytotrophoblast (dashed arrow) or stroma (solid arrow) (b) PHM with positive nuclear staining of both villous cytotrophoblast and stroma (c) discordant p57 staining in a mosaic conception with no p57 staining of the cytotrophoblast but p57-positive staining of the villous stroma (d) discordant p57 staining in a mosaic with p57positive staining of the cytotrophoblast but no staining of the villous stroma. Positive staining of extravillous trophoblast (arrow head) acts as an internal control for staining.

\section{Figure 3: Genotyping of parents and molar villi}

The $x$ axis represents the size of the DNA fragments generated (alleles are annotated beneath each peak). The y axis represents arbitrary units of fluorescent intensity (a) $\mathrm{CHM}$ in which all alleles originate from the father of the pregnancy (blue arrowheads) and no maternal alleles are detected. A single allele at each locus is indicative of a mole derived from a single sperm. 
(b) PHM in which three distinct alleles are present at the $\mathrm{TH} 01$ locus, one of maternal (red arrowhead) and two of paternal (blue arrowhead) origin, indicative of a dispermic, diandric triploid conception. At the other two loci, the paternal allele is detected at twice the intensity of the maternal allele, consistent with diandric triploidy.

\section{Figure 4: Genotyping of recurrent hydatidiform moles}

Genotyping of HM in a 34 year-old woman with two HM, showing atypical morphology and p57-negative immunostaining, and no other pregnancies. In both HM, each locus contains peaks of equivalent height, one peak matching the maternal sample (red or orange arrowhead) whilst the other is nonmaternal (blue or black arrowhead), indicating a diploid, biparental origin and a diagnosis of $\mathrm{FRHM}$, The patient was subsequently referred for sequencing of NLRP7 and KHDC3L.

\section{Figure 5.Genotyping of trophoblastic tumours}

(a) PSTT from a 38-year-old patient with two prior pregnancies. At the TPOX and D18S51 loci, alleles of maternal (red arrowhead) and paternal (blue arrowhead) origin are identifiable. The VWA locus is not informative as one allele is common to both parents. (b) Case from a 39-year-old patient with one prior pregnancy (twins) presenting with a poorly differentiated lung tumour with choriocarcinomatous differentiation. All alleles present in the tumour match the maternal alleles (red arrowheads), with none of the paternal alleles detected in the tumour. Loss-of-heterozygosity is present at the D16S539 (unfilled arrowhead). 